\title{
LOS MANUALES ESCOLARES COMO POSIBILIDAD INVESTIGATIVA PARA LA HISTORIA DE LA EDUCACIÓN: ELEMENTOS PARA UNA DEFINICIÓN
}

\author{
Gabriel David Samacá Alonso \\ Universidad Industrial de Santander-Colombia \\ davidsalon16@gmail.com
}

Recepción: 02/04/2011

Evaluación: 25/05/2011

Aceptación: 22/06/2011

Artículo de Reflexión

\section{RESUMEN}

El presente artículo pretende compartir una reflexión sobre los manuales escolares como fuente para la historia de la educación. Tal cometido parte de la premisa de la necesidad de contribuir a una definición amplia y compleja del manual escolar, reconociéndolo como un artefacto cultural que puede ser analizado desde diferentes ángulos. El manual se puede entender como una herramienta pedagógica, una mercancía del mundo editorial así como un vector cultural que vehicula valores en la sociedad. Aunque en el país la investigación con base en esta fuente se inició hace algunas décadas, consideramos que es necesario volver la mirada hacia la misma, con el fin de iniciar trabajos historiográficos que ausculten la historia de la educación, particularmente la enseñanza de la historia, desde diferentes ópticas facilitadas por los manuales escolares. Metodológicamente, este trabajo se desarrolló a partir de la revisión crítica de la bibliografía especializada en contraste con algunos manuales escolares empleados en la educación

\footnotetext{
${ }^{1}$ Historiador, candidato a Magíster en Historia y profesor Cátedra de la Universidad Industrial de Santander. Miembro del grupo de investigación Políticas, Sociabilidades y Representaciones Histórico-Educativas.
} 
básica secundaria en la década de los noventa. Además de los elementos abstractos propuestos, es necesario recordar que la noción de manual escolar es histórica, de allí la pertinencia de acometer una caracterización de sus principales atributos en diferentes momentos históricos.

Palabras clave: Revista Historia de la Educación Latinoamericana, manual escolar, dimensiones de un manual escolar, historia de la educación.

\title{
THE SCHOOL MANUALS AS A POSSIBILITY OF RESERACH FOR THE HISTORY OF THE EDUCATION: ELEMENTS FOR A DEFINITION
}

\author{
Gabriel David Samacá Alonso \\ Universidad Industrial de Santander-Colombia \\ davidsalon16@gmail.com
}

\begin{abstract}
The present article tries to share a reflection about the school manuals as source for the history of the education. Such an assignment departs from the premise of the need to contribute to a wide and complex definition of the school manual, recognizing it as a cultural factor that can be analyzed from different points of view. The manual can be understood as a pedagogic tool, a good of the publishing world as well as a cultural vector that transports value for the society. Though in the country the research with base in this source began some decades ago, we think that it is necessary to turn the look towards the same one, in order works initiate history-graphic that auscultate the history of the education, particularly the education of the history, from different optical facilitated by the school manuals.

Methodologically, this work developed from the critical review of the bibliography specialized in contrast with some school manuals used in the basic secondary education in the decade of the nineties. Besides the abstract proposed elements, it is necessary to remember that the notion of school manual is historical, of there the relevancy of undertaking a characterization of its principal attributes in different historical moments.

Key words: Journal of Latin American Education History, school manual, dimensions of a scholar manual, history of the education.
\end{abstract}




\title{
OS MANUAIS ESCOLARES COMO POSSIBILIDADE PESQUISA PARA A HISTÓRIA DA EDUCAÇÃO: ELEMENTTOS PARA UNA DEFINIÇÃO
}

\author{
Gabriel David Samacá Alonso \\ Universidade Industrial de Santander-Colômbia \\ davidsalon16@gmail.com
}

\section{RESUMO}

O presente artigo pretende compartilhar uma reflexão sobre os manuais escolares como fonte para a história da educação. Tal obrigação parte da premissa da necessidade de contribuir para uma definição ampla e complexa do manual escolar, reconhecendo-o como um artefato cultural que pode ser analisado desde diferentes ângulos. O manual pode ser entendido como uma ferramenta pedagógica, uma mercadoria do mundo editorial assim como um vetor cultural que veicula valores na sociedade. Ainda que no país a pesquisa com base nessa fonte se iniciou há algumas décadas, consideramos que é necessário voltar ao início, com o objetivo de iniciar trabalhos historiográficos que auscultem a história da educação, particularmente o ensino de história, a partir de diferentes olhares facilitados pelos manuais escolares. Metodologicamente, este trabalho se desenvolveu a partir da revisão crítica da bibliografia especializada em contraste com alguns manuais escolares empregados na educação básica secundária na década de 90 . Além dos elementos abstratos propostos, é necessário recordar que a noção de manual escolar é histórica, daí a pertinência de acometer uma caracterização de seus principais atributos em diferentes momentos históricos.

Palavras-chave: Revista História da Educação Latino-americana, manual escolar, dimensiones de um manual escolar, história da educação. 


\section{INTRODUCCIÓN}

En la historiografía de la educación colombiana los estudios con base en manuales escolares no sobrepasan las dos décadas. La gran mayoría de trabajos no se preocupan por ahondar en la categoría "manual escolar", aunque algunos hacen la salvedad en el uso práctico de diferentes nociones tales como textos escolares o libros de texto, sin apuntalar la diferencia conceptual que esto implica. Si bien compartimos la necesidad de emplear esos términos, nos percatamos igualmente del deber de señalar las distinciones entre estas categorías, además de mostrar que la definición del concepto 'manual escolar' va más allá de la simple transcripción de una sola idea al respecto.

En las siguientes cuartillas nos proponemos ofrecer una serie de entradas para desentrañar lo que se puede entender por Manual Escolar. Una definición amplia y compleja de esta noción, puede convertirse en un primer paso para definir una agenda investigativa en la historia de la educación. El artículo se estructura entonces a partir de cinco ideas: La primera, obedece a la construcción de una definición a partir del uso que se le da en el ámbito escolar, lo que nos lleva a plantear la diferencia entre manual escolar, texto escolar, libro de texto y libro escolar. La segunda idea, hace referencia a la búsqueda de una definición más allá del ámbito escolar, pensando las dimensiones del manual escolar y la tesis del manual como espacio de memoria y dispositivo. La tercera, atañe a las partes en que se puede dividir el texto escolar, a saber: texto, para texto e imágenes. En la cuarta idea, mencionaremos sucintamente las posibilidades investigativas que existen desde los manuales escolares, para finalizar con las principales características de los manuales escolares en las dos últimas décadas del siglo XX.

\section{Sobre la definición del manual escolar a partir del uso en el ámbito escolar}

Más allá de los criterios que se tengan en cuenta para construir una definición del manual escolar, es indubitable que la existencia de éste se debe a condiciones socio-históricas tales como la invención de la imprenta o el uso sistemático que se le ha dado en los sistemas educativos modernos. De estas condiciones se desprende una acepción del manual como una obra sistemática, secuencial, de producción serial y masiva, que se encuentra ligado a la extensión del método de 
enseñanza simultáneo, ya que éste exigía materiales de lectura idénticos para el trabajo homogéneo con el grupo de estudiantes. De esta forma, el manual escolar responde a las necesidades de un método educativo que hacia el siglo XIX con la creación de los sistemas educativos nacionales se incorporó como una herramienta de primer orden en los procesos educativos y socializadores .

La necesidad de nombrar este objeto de diferentes formas, ha generado una confusión en el uso de los conceptos, llegando al uso indiscriminado de términos como texto escolar, libro de texto, libro didáctico, libro escolar y manual escolar. La confusión se origina gracias a que el criterio central para definirlo responde al imperativo del uso en el ámbito escolar. Es decir, a todo texto o libro que se utilice en actividades educativas se le extiende cualquiera de las denominaciones mencionadas. No obstante, los especialistas en la materia han logrado diferenciar entre esta multiplicidad de términos, para llegar a una definición general de manual escolar desde el ámbito escolar, a la que nos acogemos en primera instancia.

Dos de los autores más reconocidos en los estudios sobre manuales escolares, Agustín Escolano Benito y Alain Choppin, han realizado una tipología que nos servirá para resolver la situación señalada. Escolano sugiere que desde el punto de vista pedagógico los textos empleados en la enseñanza se pueden clasificar en seis tipos, distintos a los manuales escolares: 1. Libros de iniciación, que contienen las rudimentos de la lectura y la escritura; 2. Las series cíclicas, como conjunto de textos de distintos niveles de complejidad que exponen los conocimientos de forma graduada; 3. Los modelos enciclopédicos, en los que se propone reunir en un solo volumen diferentes campos del conocimiento escolar; 4. Los libros-guía, como aquellos que se presentan como una introducción a un campo de estudio; 5 . El libro de consulta que complementa los textos básicos y 6. Los libros activos, aquellos en los que predominan los ejercicios y actividades de evaluación para que el estudiante participe activamente.

${ }^{2}$ OSSENBACH, Gabriela y SOMOZA, Miguel. (Eds.). (2001): Los Manuales Escolares como fuente para la historia de la educación en América Latina. Serie "Proyecto Manes". Madrid, UNED, p. 15. Para una breve historia del desarrollo de los manuales escolares en España, específicamente desde el siglo XIX el análisis de los diversos géneros textuales y las generaciones de los manuales, ver: ESCOLANO BENITO, Agustín. (2001): "Sobre la construcción histórica de la Manualística en España", en Revista Educación y Pedagogía. Vol. XIII N. 29-30. Medellín, Universidad de Antioquia, pp. 13-24. 
Por su parte, Choppin propone una clasificación en la que se diferencian los textos que son destinados específicamente al ámbito escolar y aquellos que adquieren esa dimensión por el uso que la escuela hace de ellos, pero que no fueron pensados ni producidos para ésta. Los primeros corresponderían a los libros escolares como tal, distinguiendo cuatro tipos: 1. los manuales, aquellos que serían utilizados en la clase con el objetivo de servir de apoyo escrito a la enseñanza de una disciplina; 2. las "ediciones clásicas", entendidas como la selección de obras clásicas de la literatura con comentarios adecuados para los escolares; 3. Las obras de referencia, tales como diccionarios o atlas y 4. Las obras para escolares, que comprenderían materiales de apoyo con el fin de reforzar, resumir y ejercitar ciertos contenidos ${ }^{3}$.

Ahora bien, esta clasificación del autor francés nos permite vislumbrar el criterio básico para empezar a definir el manual escolar, a saber, la finalidad exclusiva del uso escolar a diferencia del que se le da cualquier otro material. Como vemos, este criterio general incluye una importante variedad de materiales educativos que van desde los manuales propiamente dicho hasta los diccionarios, atlas y libros de actividades, de allí que sea necesario especificar aún más las características del manual escolar. Para ello retomaremos, la definición que proponen Ossenbach y Somoza:

La denominación "manuales escolares" abarcaria, en principio, aquellas obras concebidas con la intención expresa de ser usadas en el proceso de enseñanza-aprendizaje, indicada por su titulo, por su asignatura, nivel o modalidad, por su estructura didáctica interna, y por su contenido, que contemplaría la exposición sistemática y secuencial de una disciplina. Esta categoría de obras sería más restringida desde el punto de vista lógico que la primera (libros escolares), pero al ser la más numerosa y representativa en el grupo de las publicaciones escolares, parece oscilar entre el significado especifico y el significado más general e, incluso, tender a dar su nombre a todo el conjunto.

Esta definición es complementada con otros atributos que proporcionan un mejor manejo de la categoría. Estos elementos son: 1. La intencionalidad explícita del autor o el editor de que la obra sea usada en el ámbito escolar; 2. Los contenidos deben ser

${ }_{4}^{3}$ Ibídem., p. 18.

${ }^{4}$ OSSENBACH, Gabriela y SOMOZA, Miguel. (Eds.). (2001): óp., cit, p. 19. 
expuestos sistemáticamente; 3. Los contenidos deben estar adecuados pedagógicamente, ajustándose a un determinado nivel de complejidad y de maduración intelectual y emocional de los estudiantes; 4. Debe haber una reglamentación de los contenidos, en aspectos tales como la extensión y el tratamiento de los mismos y 5. La reglamentación supone una intervención estatal (administrativa y política) que selecciona, jerarquiza o excluye saberes y valores a transmitir, ya sea a través de la autorización expresa o tácita.

Como vemos, la última definición y los elementos señalados nos ubican en una idea más clara de la noción de manual escolar, en la medida en que señalan el campo educativo como el escenario inherente en que se despliega, para el que se elabora y en el que se consume el texto escolar. Al tiempo nos pone de presente la injerencia del poder político en la selección de los contenidos, que directa o indirectamente interviene en los componentes principales del manual escolar: los contenidos, los valores que vehicula y el trabajo pedagógico. Así pues, este abordaje del manual escolar como elemento clave del escenario escolar nos posibilita abocarnos a pensar el manual escolar como un producto cultural complejo que encierra distintas dimensiones de análisis, asunto del siguiente apartado.

\section{Dimensiones del manual escolar}

Al hablar de las dimensiones del manual escolar, pretendemos expresar la gran complejidad que entrañan estos objetos más allá de la aparente simplicidad y desdén con que se los puede apreciar, toda vez que se convierte en un constructo cultural que desempeña varias funciones al mismo tiempo, lo que obliga a descomponerlo en dimensiones de análisis. Siguiendo a Alain Choppin, el manual escolar presenta por lo menos cuatro dimensiones: Como herramienta pedagógica; es la concreción de lo que en determinada época se considera como verdadero en una disciplina; al tiempo que es una mercancía transable y vector comunicativo a través del que se transmiten ciertos valores.

El manual escolar puede entenderse como una herramienta pedagógica en la medida en que es un instrumento destinado a facilitar el aprendizaje de los estudiantes, e incluso ayuda a los mismos maestros

\footnotetext{
${ }^{5}$ Ibídem., p. 20.
} 
en la labor de enseñanza . Para los investigadores de la Universidad Tecnológica de Pereira, los textos o manuales escolares reflejan las tradiciones, innovaciones e incluso las grandes utopías pedagógicas de una época, ya que es a través de ellos que se expresan los objetivos y métodos pedagógicos. Sin embargo, la dimensión pedagógica del texto escolar no se reduce a señalar que es una herramienta en el quehacer educativo, que facilita la enseñanza-aprendizaje de ciertos conocimientos, pues como fuente histórica se pueden rastrear a partir de él los proyectos y métodos pedagógicos que la sociedad ha considerado pertinentes para modelar a las nuevas generaciones.

Junto a ello, el manual escolar es un elemento importante del currículo, sea éste entendido como todo un proyecto cultural que involucra al Estado, las escuelas y la comunidad o como la simple normatividad que regula y controla la educación a partir de documentos oficiales. El papel del texto escolar entonces a nivel pedagógico implica la tarea de traducir ese currículo para acercarlo a los maestros, quienes en su práctica pedagógica hacen uso de los materiales curriculares para desarrollar su trabajo. Esta relación entre currículo y manual escolar, puede ir desde la utilización del texto como un elemento más, hasta convertirse en el único instrumento con que cuentan los maestros para aproximarse a las directrices curriculares, resultado del nivel de confianza que se deposita en el texto en relación a otros materiales ${ }^{8}$. De esta forma, el manual escolar como herramienta pedagógica supone la relación con el currículo, la pertenencia a los materiales curriculares así como el status de instrumento clave para la práctica pedagógica de los docentes.

"CHOPPIN, Alain. (2001): "Pasado y Presente de los Manuales Escolares", en Revista Educación y Pedagogía. Vol. XIII. N. 29-30. Medellín, Universidad de Antioquia. p. 210. Siguiendo el mismo planteamiento de Choppin sobre las dimensiones del texto escolar ver: ALZATE PIEDRAHITA, María Victoria. (1998): "Los manuales escolares y los libros de iniciación a la lectura: Campo de investigación”, en Revista de Ciencias Humanas. No. 17. Pereira, Universidad Tecnológica de Pereira, pp. 89-98.

ALZATE PIEDRAHITA, María Victoria, GÓMEZ MENDOZA, Miguel Ángel y ROMERO LOAIZA, Fernando. (1999a): Textos Escolares y Representaciones Sociales de la Familia: Definiciones, Dimensiones y Campos de Investigación. Vol. I. Pereira, Universidad Tecnológica de Pereira, pp. 31-32. Desde una mirada de las Ciencias de la Educación y las posiciones que suscitan los textos escolares respecto a su uso ver: ALZATE PIEDRAHITA, María Victoria. (1999): "El texto escolar como instrumento pedagógico: Partidarios y detractores", en Revista de Ciencias Humanas. No. 21. Pereira, Universidad Tecnológica de Pereira, pp. 110-118. Otra mirada, que se funda en los planteamientos de Michel Foucault y su categoría de dispositivo para comprender los hilos didácticos que entraña el texto escolar, ver: PALACIO MEJÍA, Luz Victoria y RAMÍREZ FRANCO, Marta Luz. (1998): "Reflexiones sobre el texto escolar como dispositivo", en Revista Educación y Pedagogía. Vol. X. N. 21. Medellín, Universidad de Antioquia, pp. 217-235.

Ibídem., pp. 41-50. 
Si el manual escolar hace parte del utillaje central de los educadores, tiene otra dimensión cercana al ámbito escolar, aquella que se refiere al status que cobran los conocimientos consignados en los manuales en el mundo del saber. En otras palabras, el texto escolar se convierte en el soporte de las "verdades" que la sociedad cree que es necesario transmitir a las jóvenes generaciones. En palabras de Choppin:

\section{[...] el manual se presenta como el soporte, el depositario} de los conocimientos y de las técnicas que en un momento dado una sociedad cree oportuno que la juventud debe adquirir para la perpetuación de sus valores. Los programas oficiales, cuando existen, constituyen la estructura sobre la cual los manuales deben conformarse estrictamente.

Como vemos, esta dimensión pone de presente que el manual tiene una relación con los campos del conocimiento académico, que volcado al nivel escolar revelan lo que se considera cierto y digno de transmitir por parte de ciertos sectores o grupos sociales, ya que como bien señala Choppin, lo "verdadero" y "útil" puede variar de acuerdo a los lugares, las épocas, el régimen político o la confesión religiosa, lo que nos llama a plantear la historicidad de los contenidos de los manuales.

Esta segunda dimensión se relaciona con la transposición didáctica. En líneas generales, esta hace referencia a los procesos de creación del conocimiento didáctico por parte de diferentes sujetos con base en un conocimiento "extratextual" que puede corresponder al acumulado de las diferentes disciplinas científicas, dándose el paso del texto "experto" al texto escolar. Este conocimiento que contienen los manuales, es producto de operaciones de selección, simplificación, reordenamiento y esquematización de algunas fuentes de las que beben los sujetos productores de los textos, que obedecen a lo que se considera como en un momento específico como verdadero y digno de ser transmitido y aprendido por las nuevas generaciones .

El manual escolar además de estar vinculado a los conocimientos disciplinares y tener en el ámbito escolar su escenario inherente, es

${ }_{10}^{9}$ CHOPPIN, Alain. (2011): óp., cit, p. 210.

${ }^{10}$ ALZATE PIEDRAHITA, María Victoria, GÓMEZ MENDOZA, Miguel Ángel y ROMERO LOAIZA, Fernando... óp., cit, pp. 50-54. Para profundizar en el proceso de transposición didáctica ver: MATTOZZI, Ivo. (1999) "La Transposición del Texto Historiográfico: Un problema crucial de la Didáctica de la Historia". Disponible en la red vía: http://www.saber.ula.ve/bitstream/123456789/23934/1/num4_ivo_ mattozzi.pdf [20de octubre de 2009] 
también un libro, un objeto material que hace parte de un proceso de producción, comercialización y consumo. Esta dimensión permite pensar el texto escolar no ya como concepto sino como una mercancía que depende entre otras variables, del estado y progreso tecnológico, de las relaciones y condiciones económicas que atraviesan la producción, la comercialización, distribución y consumo del texto. En últimas, es un objeto que depende para su existencia de un contexto económico en el que intervienen diversos agentes e instituciones ${ }^{11}$. Junto a ese marco económico que hace posible la producción de los textos, se instala otro ámbito que permite la existencia de los manuales, este es el del diseño y la publicidad, ámbitos que aportan elementos para la confección de los textos y que aluden directamente a su materialidad.

Finalmente, el manual escolar es un vector o medio de comunicación por el que se difunden sistemas de valores, ideologías y en general imágenes de los grupos sociales y de la sociedad en que emergen, que han sido empleados como mecanismos socializadores para las nuevas generaciones. El manual escolar puede contener concepciones ideológicas, morales, religiosas, políticas, éticas, antropológicas y proyectos de sociedad, de manera explícita o tácita, tanto en lo que dice como en lo que calla ${ }^{12}$. Con base en esto, es posible pensar en un análisis del manual escolar no sólo como un instrumento para la educación sino como un registro en el que se pueden rastrear procesos culturales y políticos allende las fronteras de las instituciones educativas, desde distintas perspectivas entre las que cabe destacar la histórica, la sociológica, la antropológica y la comunicacional.

Esta dimensión del manual escolar, como vehículo de información sobre las sociedades que los ven emerger, puede concebirse de diferentes formas, en la medida en que se aproximen a problemas teóricoconceptuales relacionados con categorías como imaginario, mentalidad e ideología. Si bien nosotros no pretendemos resolver este debate teórico, señalaremos algunas ideas en torno al abordaje del texto como fuente para indagar la ideología de los grupos sociales centradas en el texto como un espacio/lugar de memoria y como dispositivo, enfoques que permiten entender el manual desde y más allá del escenario escolar.

\footnotetext{
${ }_{12}^{11}$ CHOPPIN, Alain. (2011): óp., cit, p. 211.

${ }^{12}$ Ibídem., p. 210 y OSSENBACH, Gabriela y SOMOZA, Miguel. (Eds.): óp., cit, p. 24.
} 
Siguiendo a los investigadores de la UTP, pensar el manual escolar como un vector cultural significa investirlo de la función de vehicular los valores a transmitir, donde los elementos intrínsecos del texto, tales como el diseño, los temas, la organización, jerarquización y presentación del conocimiento, no sólo obedecen a requerimientos didáctico-pedagógicos sino también a referentes políticos, morales y culturales implícitos. Los sesgos ideológicos no necesariamente han de presentarse expresamente haciendo proselitismo por algún proyecto o personaje. Por el contrario, pueden manifestarse mediante los énfasis dados a algunos temas y el correlativo silencio de otros, la perspectiva que se ofrece sobre tal o cual evento -que puede estar mediada por la pertenencia a la nación, a la clase, a la etnia o al géneroel encubrimiento de hechos, los beneficios de inventario que se les otorga a los dirigentes o las alusiones negativas o estereotipadas de los catalogados como "otros". Todas estas son formas de imprimir una orientación ideológica en los manuales escolares, a partir de saberes esquemáticos y simplificados que reafirman estereotipos de toda índole legitimando órdenes sociales imperantes ${ }^{13}$.

Esta forma de concebir el manual, como portador de ciertos valores culturales de una época, puede complementarse entendiéndolo como un espacio de memoria. Para Agustín Benito Escolano, el manual escolar - retomando la tesis de las dimensiones del mismo pero en otra clave- puede ser considerado como un elemento crucial al escribir la gramática de la memoria escolar. El texto puede ser considerado la materialización de los programas en que se concretó la cultura escolar de una época determinada, así como de los modos de comunicaciónapropiación de los contenidos y un registro de las imágenes y valores dominantes. Estas tres posibilidades de lectura del manual como fuente para la historiografía, permite pensarlo como el soporte curricular por excelencia, espejo de la sociedad que lo crea y huella de los modos y procesos de la comunicación pedagógica (memoria de los métodos de enseñanza y aprendizaje) ${ }^{14}$.

La definición del manual escolar como espacio de memoria no sólo obedece a la valoración como fuente histórica o como huella de

\footnotetext{
${ }^{13}$ ALZATE PIEDRAHITA, María Victoria, GÓMEZ MENDOZA, Miguel Ángel y ROMERO LOAIZA, Fernando. (1999b): óp., cit, pp. 58-67.

ESCOLANO BENITO, Agustín. (2001): El Libro como Espacio de Memoria, en Los Manuales Escolares como fuente para la historia de la educación en América Latina. OSSENBACH, Gabriela y SOMOZA, Miguel. (Eds.). Madrid. UNED, pp. 35-40.
} 
las dimensiones que comporta. Aunado a ello, Escolano sugiere que el manual implica una representación del mundo que lo escribe y de la cultura que se lo apropia, en otras palabras, de las cogniciones de sus autores y usuarios que conllevan un sentido, percibido como un acuerdo semántico por todos los sujetos del grupo por el que circulan los textos. Con base en Henri Giroux, Escolano señala que junto al capital cultural que circula en los textos, estos se hallan dentro unos circuitos de poder, -sea este económico o político- que reflejan toda una economía política, por ejemplo en la producción de los textos por parte de corporaciones transnacionales para todo un continente. Otro asunto de gran relevancia para comprender cómo el manual puede considerarse un espacio de memoria, tiene que ver con el componente de autoridad que entraña el texto, en la medida en que como conjunto sistemático de datos seleccionados y ordenados para ser enseñados, ha configurado la misma enseñanza, determinando los roles de los docentes y la práctica pedagógica. El texto se convierte en memoria y escritura de la cultura.

Ahora, cabe preguntarse, ¿Hablar de los manuales escolares, como espejos de la sociedad implica que sólo vehiculan aquellos mensajes ideológicos ligados a un proyecto político? o ¿Se pueden rastrear otro tipo de imágenes en los manuales? Ante estas preguntas, Escolano Benito plantea que sí bien los manuales escolares pueden ser leídos como un espejo de la sociedad que los produce, las imágenes de la sociedad comportan los valores imperantes, las actitudes, los estereotipos e ideologías que caracterizan el "imaginario" de una época, que en el decir de Escolano, representan "un correlato de la mentalidad colectiva dominante".

En consecuencia, cuando se habla de la relación manual escolarmemoria-vector cultural, nos estamos refiriendo no sólo a los mensajes ideológicos sino además a las representaciones que conforman el imaginario de una sociedad. Se trasciende el nivel de las estrategias de influencia derivadas de la difusión del núcleo dogmático de un sistema político para llegar al reflejo de las tradiciones mentales arraigadas, transmitidas a través de las costumbres y la educación, reforzadas como valores a mantener con el orden nuevo. En otras palabras, el manual como vector cultural puede contener tanto elementos de adoctrinamiento político como mecanismos de socialización cultural

${ }^{15}$ Ibídem., pp. 41-44. 
que aseguran la transmisión del imaginario colectivo, aunque en la realidad, tal distinción sea difícil de sostener .

\section{Sobre las partes de un texto escolar}

Hasta este momento hemos podido reconocer que el manual escolar como objeto cultural comporta una gran complejidad, que se expresa en una multiplicidad de dimensiones interconectadas, exigiendo un análisis desde diferentes ángulos para aprehender la riqueza que encierra. Sin embargo, surge la inquietud de si el manual ha de pensarse como una unidad homogénea y compacta que internamente no admite ninguna descomposición analítica, o sí por el contrario puede ser sometido a un análisis más detallado. Con base en los trabajos de María Victoria Alzate y otros investigadores de la UTP, procuraremos responder la pregunta formulada, partiendo de la premisa de que en la construcción de una definición del manual escolar, hay que tener en cuenta su organización interna.

Para Alzate Piedrahita la estructura interior de un manual escolar responde a ciertas reglas, que lo configuran en sus principales partes, dirigiendo incluso la lectura del texto, o lo que es lo mismo, interviniendo en las condiciones de uso. La autora que seguimos sugiere que un manual escolar se puede dividir en tres grandes partes, a saber: el texto, el paratexto y las imágenes . Cabe mencionar que la relación entre estos tres elementos ha variado de acuerdo al momento histórico, por ejemplo, a mediados del siglo XX la proporción entre el número y el lugar de las imágenes frente al texto escrito era diferente a la de los textos de las últimas dos décadas de este mismo siglo. Además, cada una de las partes señaladas es susceptible de ser analizada más a fondo, tal y como lo veremos con los tipos de texto que se pueden hallar en un manual, las diferentes imágenes y la complejidad del llamado paratexto.

\footnotetext{
${ }^{16}$ Ibídem., pp. 44-46. Una característica relevante de la relación entre estos dos ámbitos culturales (la ideología y el imaginario) respecto a los textos escolares, alude a que los clisés del imaginario (por ejemplo, los que se refieren a los roles de los géneros, cuestiones étnicas, entre otras) cambian muy lentamente y no siempre en función de las transformaciones de tipo político, que sí pueden hacer mutar más rápidamente los valores e intereses a expresar en los manuales. Esta distinción nos ayuda a diferenciar un tanto más, aquellos aspectos que se pueden rastrear en los textos.

ALZATE PIEDRAHITA, María Victoria. (1999): “¿Cómo leer un texto escolar?: Texto, paratexto e imágenes", en Revista de Ciencias Humanas. No. 20. Pereira, Universidad Tecnológica de Pereira, p. 115.
} 
El texto en un manual escolar -entendido como una unidad sintáctico/semántica- se articula en parágrafos, que generalmente se hayan organizados en capítulos provistos de un número. Un manual se compone de varios tipos de textos, que no tienen el mismo peso ni status, dependiendo de la disciplina que se trate. Dentro de los principales tipos de texto que podemos encontrar destacamos seis. En primer lugar, tenemos el texto narrativo que se caracteriza por el empleo del pasado simple o del presente utilizado para narrar, de allí que se inscriban en una dimensión cronológica para dar cuenta de las evoluciones, dinámicas y cambios. En segundo lugar, están los textos descriptivos que utilizan el presente y se prestan para describir los fenómenos habituales o verdades de orden general, sobre todo en las síntesis o en las conclusiones.

En tercer lugar, se puede encontrar el texto argumentativo, que se caracteriza por el uso del tiempo presente así como por la presencia de conectores lógicos. Un cuarto tipo de texto es el explicativo, que justifica una noción a partir de la exposición de los argumentos, al tiempo que consolida una opinión. El quinto texto destacado por la autora es el denominado texto conminatorio, utilizado para dar o impartir órdenes, de allí el recurso al imperativo o al futuro asociado a los textos de urbanidad o de las ciencias naturales y su método experimental, específicamente en las pruebas de laboratorio y en general en las actividades propuestas para los estudiantes. Por último, se presentan los textos históricos o documentales, que corresponden a los testimonios tomados de autores contemporáneos o pasados, de lo que se infiere que no son redactados por el autor del manual, quien los escoge y en ocasiones anota o titula para orientar al lector ${ }^{18}$.

Esta tipología de los textos que se pueden encontrar en los manuales escolares constituye una de las partes más importantes, puesto que es allí donde principalmente se desarrollan los contenidos a enseñar y se vehiculan los valores, cobrando existencia en las unidades de lectura. De esta forma, los textos alcanzan coherencia en la lección que constituye la unidad de lectura por excelencia, puede estar conformada por un capítulo o por una parte del mismo, es decir, el texto escrito se estructura en unidades de lección, las más de las veces a partir de la figura del capítulo y sus apartados . En la definición de la unidad de

\footnotetext{
${ }_{19}^{18}$ Ibídem., pp. 116-117.

Ibídem., p. 117.
} 
lectura cumplen un gran papel los diversos procedimientos tipográficos, a partir de los que es posible visualizar y distinguir las jerarquías que organizan la lectura, haciéndose partícipe de este modo la tipografía en el sentido de los textos ${ }^{20}$.

Como segunda parte relevante de los manuales, la autora plantea la existencia del paratexto. Este consiste en aquellos elementos que hacen parte del diseño del texto con incidencia en la lectura del mismo. Una primera definición del paratexto comprende los títulos, subtítulos, paginación, notas, referencias, blancos e ilustraciones, dentro de las que caben también los elementos que son referidos a través de notas de pie, como documentos o glosarios. Otra definición del paratexto, considera que éste además de los elementos citados, contempla otra serie de objetos que darían lugar a la constitución de un sistema paratextual del acto educativo, en que el manual escolar sería el eje central y los otros objetos girarían en torno a él. Dentro de los objetos contemplados en el sistema paratextual la autora incluye: Libros de lectura; libros de bolsillo; libros de fuentes primarias; atlas geográficos o históricos; guías para el profesor; revistas para maestros; libros de actividades; e incluso materiales audiovisuales, sólidos, reproducibles (como guías para fotocopiar) y de software con fines educativos ${ }^{21}$. La idea de paratexto corresponde a aquel conjunto de elementos que gravitan alrededor del texto escrito o del manual, es decir, como elementos del diseño que manual o el cúmulo de materiales curriculares que inciden en la producción y uso del texto escolar.

El último elemento que constituye el orden interno del texto escolar es la imagen, que comprende todo lo que no es signo lingüístico ni matemático. Se puede decir que es una representación de la realidad, aunque hay diferentes tipos de imágenes incluidas en los manuales escolares. Para dilucidar esta situación, se ha definido una escala de iconicidad decreciente para clasificar las imágenes según su grado de realismo en relación a la presentación. De ella, se deriva una tipología de imágenes de la más realista a la menos realista: las fotografías, los dibujos y los esquemas. Las fotografías, especialmente a color son

\footnotetext{
${ }^{20}$ Dentro de los recursos tipográficos empleados para resaltar ideas o nociones, que se juzgan como esenciales para memorizar o comprender, se destacan: los caracteres tipográficos (cuerpos, estilos, filas, etc.), los encuadres, los fondos tramados en color, la organización de la página (en columna o margen), subrayados, saltos de línea, entradas, entre otros.

Ibídem., pp. 115 y 118.
} 
las imágenes con mayor grado de realismo y las que generan mayor atracción, aunque como se sabe éstas no pueden ser tomadas como un testimonio objetivo, por factores como el encuadre, la selección del campo, el ángulo de la toma, la luz, la escala, entre otros elementos que entran a jugar en el sentido que imprime tanto el fotógrafo como quien la incluye en un manual escolar. Por su parte, los dibujos permiten una lectura más clara de la intención del autor, en la medida en que resaltan los aspectos esenciales, apuntando a la generalidad, tal y como se puede apreciar en los textos de Geografía. Los esquemas tienen como característica modificar la realidad para hacerla más concreta y accesible, ya que permiten visualizar datos abstractos por medio de figuras sencillas, tal es el caso de los esquemas, mapas conceptuales y esquemas de los textos de Historia o de Ciencias Sociales en general, que buscan poner de presente relaciones lógicas de difícil comprensión para los estudiantes .

No obstante esta tipología básica, las imágenes que aparecen en un manual escolar toman el carácter de documento que tiene para el lector una función pedagógica. Esta situación se desarrolla a partir de factores como la organización interna de la imagen, su posición en relación al contexto en que se encuentre, de lo que se deriva una nueva clasificación: aquellas imágenes que fueron creadas exclusivamente para el manual escolar (mapas, diagramas, dibujos) y cuyo destinatario es el público escolar y las imágenes que no fueron concebidas para ello pero que se utilizan dentro de un texto (cuadro, caricatura, afiche), que demanda un trabajo de adaptación al soporte escolar, consistente entre otras cosas en el ajuste de escala, encuadre, tamaño, disposición en la página, etc.

Por otra parte, los autores han definido que existen varias forma de dotar de sentido a las imágenes de los manuales escolares, dentro de los métodos que se destacan están: por el texto o anclaje de la foto, por la relación con otras imágenes, por la percepción global o de conjunto de una serie de imágenes, por el juego de variables internas y externas, entre otros. Las imágenes que se incluyen en los textos cumplen unas funciones específicas, entre las que se pueden mencionar: motivación al lector para llamar la atención en estrecha relación con el texto; decorativa, en la que sólo incluye por motivos estéticos y no por razones pedagógicas; información, tal y como sucede con los dibujos que resaltan lo esencial y puede complementar o explicitar el texto;

${ }^{22}$ Ibíd., pp. 118-119. 
reflexión, en cuanto la imagen puede estar acompañada de preguntas dirigidas al lector y puede preceder al texto $\mathrm{y}_{23}$ ejemplo, donde se da una parafrase del texto sin llegar a ser decorativa.

\section{De los campos de investigación}

Las posibilidades investigativas que entrañan los manuales escolares dependen fuertemente de la definición que construyamos de este artefacto cultural. En este sentido, es preciso mencionar algunas de las ventanas de indagación que estos ofrecen, con el fin de hacernos a una idea más cercana a la complejidad a que hemos hecho referencia. En este orden de ideas, procuraremos enunciar los campos de investigación recurrente en el mundo de los manuales escolares así como los nuevos retos que se abren en la contemporaneidad, lo que al tiempo nos obliga a hacer mención de aquellas problemáticas olvidadas o descuidadas por parte de los investigadores, pero que constituyen valiosos espacios de trabajo. Cabe mencionar que la gran mayoría de los textos consultados tratan en alguna medida las oportunidades investigativas que traen los manuales escolares, debido a la relativa novedad de los trabajos así como por el amplísimo espectro que comporta este tipo de fuente, resultado apenas obvio con la multiplicidad de dimensiones que encierran.

El proyecto MANES, sostiene que de las investigaciones realizadas con base en este tipo de documentos han prevalecido alrededor de cuatro campos. En primer lugar, y de forma dominante los trabajos se han centrado en la problemática de la construcción de las identidades nacionales y de imaginarios colectivos, gracias a la centralidad de la educación y de los manuales en la configuración de los Estados-Nación en el continente y los procesos de homogenización inherentes. ${ }^{24}$ Paralelo a estos trabajos, se han desarrollado otros que con una mirada similar se han centrado en el tránsito de la moral religiosa a una moral más laica y social, ubicándolos en el estudio de los procesos de secularización a través de los manuales escolares ${ }^{25}$. Otros trabajos relacionados con la

${ }^{23}$ Ibídem., pp. 119-121. Además de ALZATE PIEDRAHITA, María Victoria, GÓMEZ MENDOZA Miguel Ángel y ROMERO LOAIZA, Fernando. (1999b): "La iconografía en los textos escolares de ciencias sociales", en Revista de Ciencias ${ }_{24}$ umanas. No. 22. Pereira, Universidad Tecnológica de Pereira, pp. 102-110.

${ }^{24}$ GUEREÑA, Jean-Louis, OSSENBACH, Gabriela y DEL POZO, María del Mar. (Dirs.). (2005): Manuales Escolares en España, Portugal y América Latina (Siglos XIX y XX). Madrid, UNED, pp. 36-40.

OSSENBACH, Gabriela y SOMOZA, Miguel. (Eds.). (2001): óp., cit, p. 26-27. 
dimensión identitaria son los relacionados con la higiene y el control social y político que desde las especificidades culturales se presentan.

Una tendencia interesante que se ha venido abriendo campo en el mundo de las investigaciones sobre manuales tiene que ver con la edición escolar. Esta línea de trabajo, aborda tanto las editoriales como a los autores de los textos escolares, en tanto cubre todo el proceso de producción y difusión de los manuales. Tal es el caso de las empresas multinacionales que cubren el mercado del texto escolar, las biografías intelectuales de los autores hasta los contextos culturales e ideológicos en los que los autores acometían su labor. Una tercera línea de trabajo consiste en investigaciones sobre los manuales para la formación de profesores, a partir de la que se pueden reconstruir asuntos tan importantes como la evolución de la Pedagogía y de las Ciencias de la Educación en su camino por constituirse como disciplina científica.

En la misma dirección se pueden mirar los procesos de profesionalización de los maestros, centrándose en la historia de las Escuelas Normales o facultades de Educación. Por último, el proyecto MANES referencia los trabajos que se centran en el estudio de disciplinas específicas, cuyos resultados se ubican en el marco de lo que se ha empezado a denominar la historia del currículum escolar o de las disciplinas escolares, puesto que se preocupan por los contenidos curriculares como por las especificidades didácticas de las materias que se enseñan ${ }^{27}$. Estos serían los principales campos de trabajos que a nivel iberoamericano se han venido desarrollando en los últimos años, que desde luego no agotan el potencial investigativo que comportan los manuales escolares.

Si bien las cuatro líneas mencionadas de por sí constituyen vastos terrenos fértiles para la investigación, existe una larga lista de otros campos en los que se pueden iniciar investigaciones o en los cuales en diferentes puntos de Iberoamérica ya se han dado los primeros pasos. Dentro de los posibles temas a incluir se pueden contar: El abordaje de disciplinas no humanísticas para rastrear la evolución e influencia de

\footnotetext{
${ }_{27}^{26}$ Ibídem., p. 27.

${ }^{27}$ GUEREÑA, Jean-Louis, OSSENBACH, Gabriela y DEL POZO, María del Mar. (Dir.): óp., cit, p. 20-36. Para el caso de la historia de la historiografía escolar como nuevo campo de estudio podemos referirnos a los trabajos de Rafael Valls Montes, específicamente: VALLS MONTES, Rafael. (1999): "De los manuales de historia a la historia de la disciplina escolar: Nuevos enfoques en los estudios sobre la historiografía escolar española”. Disponible en la red vía: http://www.ub.es/histodidactica/articulos/vallsmontes.htm [22 de noviembre de 2010]
} 
corrientes pedagógicas; el estudio de la influencia de estas corrientes en distintas épocas y su posible adopción en el marco de coyunturas de cambio político o la resistencia a tal renovación; la transposición pedagógica del saber científico, que de paso permite acercarse a como se da la paulatina especialización y jerarquización de los saberes; el uso que los maestros hacen de los manuales; además de temas como la discriminación social y racial estudiando sectores como los indígenas y las mujeres, la relación entre los tipos de lenguaje presentes en los textos (currículo abierto y oculto, $l_{28}$ textual y lo semántico), la evolución material de los textos, entre otros

Mención aparte merecen dos tipos de estudios que han caracterizado a los trabajos sobre manuales escolares, uno por su carácter pionero y el otro por su poder potencial debido a las condiciones de producción de los textos en la contemporaneidad. Nos referimos a lo que Alzate Piedrahita y compañía denominan "la política del texto escolar", que como su nombre lo indica hace referencia al estudio de la legislación en torno a este objeto cultural, ya que permite conocer la manera como el Estado ha desarrollado su política educativa, específicamente los fundamentos filosóficos y políticos sobre los que se basa. El otro campo potencial para el desarrollo de investigaciones, dependiente de las nuevas formas de producción consiste en el análisis del corpus icónico de que se han provisto los manuales contemporáneos. En el decir del estudioso de los manuales escolares de historia, Rafael Valls los estudios sobre los textos de hoy deben tener en cuenta que la proporción de imágenes ha ido en aumento, de allí la necesidad de centrar los estudios en esta masa de documentos, que antes no existían u ocupaban un lugar secundario en los manuales.

${ }^{28}$ OSSENBACH, Gabriela y SOMOZA, Miguel. (Eds.). (2001): Los manuales escolares como fuente para la historia de la educación en América Latina, óp., cit, pp. 30-34.

ALZATE PIEDRAHITA, María Victoria, GÓMEZ MENDOZA, Miguel Ángel y ROMERO LOAIZA, Fernando (1999a): óp., cit, p. 77. Por su parte Choppin aduce que el estudio del contexto legislativo y reglamentario es de suma importancia en los trabajos sobre la edición escolar, toda vez que es a partir del conocimiento de la reglamentación que formalmente tienen que seguir los editores que es posible la producción de textos escolares. Cfr. CHOPPIN, Alain. (2011): óp., cit, p. 216.

VALLS MONTES, Rafael. (2001): "Los nuevos retos de las investigaciones sobre los manuales escolares de historia: Entre textos y contextos", en Revista de Educación y Pedagogía. Vol. XIII. No. 29-30. Medellín, Universidad de Antioquia. p. 97. VALIS MONTES, Rafael. (2001): "Los estudios sobre los manuales escolares de historia y sus nuevas perspectivas." Disponible en la red vía: www.ub.es/histodidactica/articulos/ valls-montes2.htm [15 de septiembre de 2009] En otro artículo, Valls Montes reconoce la necesidad de realizar un abordaje de los textos no sólo en lo que dicen sino además en el uso que tanto estudiantes como docentes hacen de él, con el fin de construir un análisis realmente integral de este complejo artefacto cultural. Cfr. VALLS MONTES, Rafael. "De los manuales de historia a la historia de la disciplina escolar: Nuevos enfoques en los estudios sobre la historiografía escolar española" óp., cit. 
Como podemos ver, las posibilidades investigativas que se pueden construir con base en los manuales escolares son realmente amplias, las cuales exigen trabajos que abran caminos para consolidar lo que Escolano Benito denomina como "Manualística", que no hace más que dar cuenta de la complejidad y riqueza de esta fuente. Sin embargo, como plantea Choppin los estudios debieran involucrar muchas miradas sobre un mismo objeto, erigiéndose incluso como un campo de trabajo para eso que han dado en llamar la transdisciplinariedad, ya que no basta con reflexiones parciales. En palabras del historiador francés: "La historia del libro y de la edición escolares no puede pues explicarse sólo por la yuxtaposición de investigaciones puntuales que se centrarian sobre tal o cual aspecto, pero llevarian a desconocer los demás. Sólo la multiplicidad de perspectivas y de ideas permite, en un acercamiento globalizador, tejer los lazos indispensables para la comprensión de ciertos fenómenos y de su evolución",

\section{El manual escolar en las dos últimas décadas del siglo $\mathrm{XX}$}

Para cerrar este abrebocas al mundo de los manuales escolares, procuraremos abordar brevemente, algunas ideas en torno al manual escolar en las dos últimas décadas del siglo XX. Como sugerimos líneas arriba, los manuales escolares cambian con el tiempo, de allí que no sea lo mismo un catecismo republicano de la segunda mitad del siglo XIX, un texto de la primer mitad del siglo XX que se conocía por el apellido de su autor y en el que predominaba el texto escrito, o los actuales manuales que apuestan por una hipertextualidad a la usanza de las nuevas tecnologías de la información y la comunicación. Los manuales en los que predomina la imagen, el color y nueva forma de elaborar contenidos obedecen, como todas las generaciones de manuales, a unas condiciones históricas y proyectos sociopolíticos específicos. En este sentido, enunciaremos de manera general algunas de las principales características de este nuevo tipo de manuales, con el fin de complementar la definición de manual escolar que hemos tratado de construir.

Las transformaciones en los manuales escolares se dieron en varios lugares del mundo durante la segunda mitad del siglo XX, de allí que encontremos situaciones similares en países como Francia, España y Argentina. Para el caso francés, señala Choppin que luego de

31 ESCOLANO BENITO, Agustín. "Sobre la construcción histórica de la

Manualística en España” óp., cit.

CHOPPIN, Alain. (2011):óp., cit, p. 215. 
la II Guerra Mundial, las revistas ilustradas entraron en competencia con los manuales vigentes hasta ese momento (modelo catequístico y enciclopédico) para dar paso a la preocupación por convertir a los manuales en objetos atractivos para los jóvenes consumidores. De esta forma, desde la década del treinta pero sobre todo desde los años sesenta, se acentuó la tendencia en la producción de los textos escolares por incluir más imágenes, restándole espacio al texto escrito. Al tiempo que se introdujo de manera permanente la ampliación de los colores (cuatricromía), así como cambios en la presentación que se acompañan con variaciones en los contenidos producto de reformas educativas y la adhesión al proyecto democratizador como paradigma de la organización social y política. Así pues:

...los docentes no esperan hoy ya de los manuales que les presenten, a través de una progresión rigurosa, un conjunto de saberes organizados, lo que durante mucho tiempo fue su principal propósito, y condicionó su organización interna en capitulos estereotipados. El manual se ha convertido en una berramienta "polifónica": tiene que permitir la evaluación de la adquisición de conocimientos; tiene que presentar una documentación compuesta, tomada de soportes variados; tiene que facilitar la asimilación por parte de los alumnos de un cierto numero de métodos intercambiables a otras situaciones $y$, teniendo en cuenta la heterogeneidad crecięzte de públicos escolares, tiene que presentar lecturas plurales.

De allí que para el autor francés, los manuales contemporáneos se muevan entre el modelo multimedial en que el texto sigue siendo el eje del proceso educativo, pero alrededor de él gravitan materiales con objetivos pedagógicos precisos como cintas, léxicos, entre otros. Y por el otro, el modelo integrado, más económico ya que no se sale de las fronteras del mismo manual, pero que debido a la inclusión de tantos temas y herramientas, terminan por generar la confusión y la sensación de extravío tanto en el estudiante como en el mismo docente ${ }^{34}$.

Para el caso español, Escolano Benito plantea que desde la década del setenta el mundo de la producción de textos escolares cambió gracias al influjo de múltiples disciplinas y campos de conocimiento, entre los que se destacan la Psicopedagogía, la Didáctica, la Lingüística,

\footnotetext{
${ }_{34}^{33}$ Ibídem., p. 228.

Ibídem, p. 228.
} 
la Iconología y las modernas Tecnologías de la Comunicación, las cuales habrían generado una "revolución en la manualística". Al igual que en el caso francés, desde inicios de la segunda mitad del siglo XX se dieron los primeros pasos en la dirección de cambiar la misma concepción del manual. Las transformaciones iban desde la preocupación por el público infantil y juvenil, el empleo de nuevas técnicas de redacción, el uso de un vocabulario específico, la inclusión de cualidades estéticas, todo lo cual se apoyó en nuevas reglamentaciones estatales sobre la producción de manuales. Este nuevo panorama fue producto de la concurrencia e interacción de nuevos discursos por parte de disciplinas emergentes, reglamentación desde el Estado e iniciativas experimentales de autores y editores, en cuya definición intervendrían equipos de diseño y producción (autores, diseñadores, ilustradores, grafistas) quienes incorporarían nuevas formas de composición literaria e iconográfica, llevando a la creación de una nueva generación de manuales ${ }^{35}$.

De la misma forma, en Argentina se dieron cambios en los manuales escolares, tanto en los contenidos como en las propuestas pedagógicas y en el diseño material de los mismos. Dentro de las causas de esta transformación, Luís Alberto Romero señala la construcción de un régimen democrático que se vio acompañado por la introducción de reformas educativas en la primera mitad de los noventa, hechos que tuvieron un impacto directo en las editoriales y sus proyectos, ya que debían acoplarse a las nuevas condiciones impuestas por el Estado. En segundo lugar, un síntoma y a la vez causa de los cambios, fue la incorporación de un nuevo tipo de autores provenientes de las universidades, quienes de una u otra forma contribuyeron a modificar los contenidos. En tercer lugar, para el caso argentino se expone como causa la transposición de métodos y técnicas introducidas en Europa, especialmente en España. Un cuarto factor lo constituiría la abierta competencia entre las editoriales por ganar el mercado de textos, de allí que se haya dado un relativo culto por lo nuevo y la correlativa actualización de los manuales.

En cuanto a los cambios más significativos se pueden mencionar los siguientes: Inicialmente las modificaciones se dieron en el diseño gráfico que amarró el trabajo de los autores y editores. Este nuevo orden

${ }^{35}$ ESCOLANO BENITO, Agustín, óp., cit., pp. 20-22. 
supuso textos más breves a favor de las ilustraciones, textos recuadrados, cuadros, páginas con temas especiales, mapas conceptuales, fuentes y citas de autoridades académicas y sobre todo un número mayor de actividades. Respecto a las actividades, estas sufrieron modificaciones además de la cantidad, puesto que ahora ocupaban lugares especiales (páginas determinadas o sitios en el desarrollo del texto), incluían trabajos desde el texto mismo además de ofrecer la posibilidad de consultar otras fuentes.

Estos cambios, pueden ser interpretados como la apertura a diferentes miradas sobre los contenidos a estudiar, que se apoyarían en la posibilidad de brindar múltiples lecturas, aunque por otro lado, se pueden entender como una implosión y fragmentación de la información y el conocimiento, inducida por cambios pedagógicos y editoriales. Esta fragmentación o apertura a la pluralidad se dio simultáneamente con la desaparición de la figura del autor y la emergencia del equipo autoral, cuyos miembros trabajan separadamente, siendo el editor el único que puede hacer converger sus trabajos, aún cuando no siempre conocen la disciplina a profundidad ${ }^{36}$.

La relevancia de mencionar estos cambios en otras latitudes, consiste en que en Colombia estos cambios se dieron de forma similar. Ahora, tal y como lo sugiere Romero, al analizar este tipo de manuales es posible determinar continuidades por debajo de la cascada de cambios de que han sido objeto, las cuales se pueden determinar en los contenidos, estén expuestos en mapas conceptuales, esquemas, lecturas o narraciones. De allí que tenga todavía vigencia adelantar investigaciones sobre la larga duración de las representaciones de la historia patria a través de los manuales escolares.

Recapitulando, la categoría de manual escolar encierra múltiples e imbricadas dimensiones. Para el caso de la historia cultural, se puede priorizar la acepción del manual como vector cultural, lo que permite centrarse en el proyecto de transmitir ciertos valores y socializar a las y los jóvenes en un proyecto de sociedad democrático liberal. No obstante, cualquier énfasis que se dé en los trabajos a emprender, debe tener en cuenta que los manuales fueron creados para que se desplegaran

${ }^{36}$ ROMERO, Luís Alberto. (Coord.). (2004): La Argentina en la escuela: la idea de nación en los textos escolares. Buenos Aires, Siglo XXI, pp. 149-151. 
en el escenario educativo, al tiempo que respondían a un estado del conocimiento investigativo. Apostar por redimensionar y problematizar la noción de manual escolar en una agenda investigativa de la historia de la educación, tiene el inmenso reto de partir de la multidimensionalidad de esta fuente histórica, lo que de una u otra forma conduce a repensar y revisar toda la disciplina. Comenzar por reflexionar sobre las categorías que empleamos puede ser un primer paso.

\section{FUENTES}

ALMARIO GARCÍA, Oscar, ORTIZ MEZA, Luís Javier y REYES CÁRDENAS, Catalina. (1992): Hombres, Espacio y Tiempo $8^{\circ}$ grado: Colombia, América y el Mundo en el siglo XIX. Medellín, Susaeta.

BURGOS, Campo Elías y NAVARRO B., Ana Victoria. (1994): Sociedad Activa 8. Bogotá, Educar Editores.

MONTENEGRO GONZÁLEZ, Augusto. (1992): Civilización 8. Bogotá, Norma. Segunda Reimpresión.

ESPINOSA PULIDO, Olga Constanza y RAMOS PEÑUELA, Clara Inés. (1997): Milenio 8: Historia y Geografía. Bogotá, Norma.

MEISELES BERNAL, Adolfo. (1991): Senderos 8: La Historiay su Paisaje Natural. Bogotá, Ediciones Cultural. Segunda edición ampliada y reformada.

GARCÍA ORTIZ, Fabio; NOREÑA, María Isabel y ROJAS, Ruth Isabel (1991): Ciencias Sociales Integradas 8. Bogotá, Voluntad.

\section{REFERENCIAS}

ALZATE PIEDRAHITA, María Victoria, GÓMEZ MENDOZA, Miguel Ángel y ROMERO LOAIZA, Fernando. (1999): "La iconografía en los textos escolares de ciencias sociales", en Revista de Ciencias Humanas. No. 22. Pereira, Universidad Tecnológica de Pereira.

ALZATE PIEDRAHITA, María Victoria, GÓMEZ MENDOZA, Miguel Ángel y ROMERO LOAIZA, Fernando. (1999): Textos Escolares y Representaciones Sociales de la Familia: Definiciones, Dimensiones y Campos de Investigación. Vol. I. Pereira, Universidad Tecnológica de Pereira.

ALZATE PIEDRAHITA, María Victoria. (1999): “¿Cómo leer un texto escolar?: Texto, paratexto e imágenes", en Revista de Ciencias Humanas. No. 20. Pereira, Universidad Tecnológica de Pereira. 
ALZATE PIEDRAHITA, María Victoria. (1999): "El texto escolar como instrumento pedagógico: Partidarios y detractores", en Revista de Ciencias Humanas. No. 21. Pereira, Universidad Tecnológica de Pereira.

ALZATE PIEDRAHITA, María Victoria. (1998): "Los manuales escolares y los libros de iniciación a la lectura: Campo de investigación", en Revista de Ciencias Humanas. No. 17. Pereira, Universidad Tecnológica de Pereira.

CHOPPIN, Alain. (2001): "Pasado y Presente de los Manuales Escolares", en Revista Educación y Pedagogía. Vol. XIII. No. 29-30. Medellín, Universidad de Antioquia.

ESCOLANO BENITO, Agustín. (2001): El Libro como Espacio de Memoria, en OSSENBACH, Gabriela y SOMOZA, Miguel. (Eds.) Los Manuales Escolares como fuente para la historia de la educación en América Latina. Madrid. UNED.

ESCOLANO BENITO, Agustín. (2001) "Sobre la construcción histórica de la Manualística en España”, en Revista Educación y Pedagogía. Vol. XIII. No. 29-30. Medellín, Universidad de Antioquia.

GUEREÑA, Jean-Louis, OSSENBACH, Gabriela y DEL POZO, María del Mar. (Directores). (2005): Manuales escolares en España, Portugal y América Latina. (Siglos XIX y XX). Madrid, UNED.

MATTOZZI, Ivo. (1999): “La Transposición Del Texto Historiográfico: Un problema crucial de la Didáctica de la Historia”. Disponible en la red vía: http:/ /www. saber.ula.ve/bitstream/123456789/23934/1/num4_ivo_mattozzi.pdf [20de octubre de 2009]

OSSENBACH, Gabriela y SOMOZA, Miguel. (Eds.). (2001): Los Manuales Escolares como fuente para la bistoria de la educación en América Latina. Madrid, UNED.

PALACIO MEJÍA, Luz Victoria y RAMÍREZ FRANCO, Marta Luz. (1998) "Reflexiones sobre el texto escolar como dispositivo", en Revista Educación y Pedagogía. Vol. X. No. 21. Medellín, Universidad de Antioquia.

ROMERO, Luís Alberto. (Coord.). (2004): La Argentina en la escuela: la idea de nación en los textos escolares. Buenos Aires, Siglo XXI.

VALLS MONTES, Rafael. (1999): "De los manuales de bistoria a la bistoria de la disciplina escolar: Nuevos enfoques en los estudios sobre la bistoriografía escolar española". Disponible en la red vía: http://www.ub.es/histodidactica/ articulos/valls-montes.htm [22 de noviembre de 2010] 
VALLS MONTES, Rafael. (2001): "Los estudios sobre los manuales escolares de bistoria y sus nuevas perspectivas.”Disponible en la red vía: www.ub.es/histodidactica/ articulos/valls-montes2.htm. [15 de septiembre de 2009]

VALLS MONTES, Rafael. (2001) "Los nuevos retos de las investigaciones sobre los manuales escolares de historia: Entre textos y contextos", en Revista Educación y Pedagogía. Vol. XIII. No. 29-30. Medellín, niversidad de Antioquia.

SAMACÁ ALONSO, Gabriel David. (2011): "Los manuales escolares como posibilidad investigativa para la historia de la educación: elementos para una definición" en: Revista Historia de la Educación Latinoamericana N. 16, Tunja, Universidad Pedagógica y Tecnológica de Colombia, RUDECOLOMBIA, SHELA- HISULA pp. 199-224 